\title{
Effect of Gravity on Flame Structure of Small-Scale Pool Fires
}

\author{
Ryo Takahashi, Hiroyuki Torikai, Akihiko Ito \\ Graduate School of Science and Technology, Hirosaki University, Hirosaki, Japan \\ Email: h15ms613@hirosaki-u.ac.jp
}

How to cite this paper: Takahashi, R., Torikai, H. and Ito, A. (2017) Effect of Gravity on Flame Structure of Small-Scale Pool Fires. Open Journal of Safety Science and Technology, 7, 96-105. https://doi.org/10.4236/ojsst.2017.73009

Received: February 3, 2017

Accepted: August 13, 2017

Published: August 17, 2017

Copyright $\odot 2017$ by authors and Scientific Research Publishing Inc. This work is licensed under the Creative Commons Attribution International License (CC BY 4.0).

http://creativecommons.org/licenses/by/4.0/ (c) (i) Open Access

\begin{abstract}
The height of the pool fire depends on the amount of heat feedback from the flame to the fuel. In order to predict flame height in a partial gravity environment, we investigated the heat feedback amount of a small pool flame experimentally under normal to partial gravity conditions; using the drop tower at Hirosaki University in Japan to obtain arbitrary partial gravity condition, which varied from $1 \mathrm{G}$ to $0.55 \mathrm{G}$. We performed the measurement of the flame shape with a digital camera. Based on the experiment result, we expected the amount of fuel vapor from the amount of heat feedback of the pool flame calculated and to establish the prediction formula of the flame height in the partial gravity environment.
\end{abstract}

\section{Keywords}

Pool Fire, Partial Gravity, Drop Tower, Liquid Fuel, Flame Structure

\section{Introduction}

In recent years, as space research and technology progress, activity range of human spreads to various gravity environments. Although a fire in a spacecraft and station is a greatly feared hazard, flame characteristics under various gravity environments are not clarified entirely. Because there is no buoyant force under microgravity environment; flame behaviour is completely different than under normal gravity environment. To predict phenomena of fires, it is important to understand the effect of gravity on flame behavior which differs depending on the buoyancy. To clarify the relationship between flame behavior and gravity, some combustion research under varied gravity environments using drop towers, parabolic-trajectory airplanes, the Space Shuttle, and centrifuges has done [1]-[9]. However, there has been little combustion research into partial-gravity environments between micro and normal gravity. 
From previous research, it is clear that the flame height of small-scale pool fires decreases as gravity levels decline [10] [11]. To clarify the mechanism of flame height decrease, flow field research and heat feedback research of pool fires was performed by Yoshihara and Yoshida et al. [10]. As a result, the mechanism of the decrease in flame height is becoming obvious. However, the relationship between the flame height and the gravity value has not yet been quantitatively shown. In this research, we performed small-scale pool fires under a partial gravity environment using the drop tower at Hirosaki University. Based on the experiment result, it is aimed to expect the amount of fuel vapor from the amount of heat feedback of the pool flame calculated and to establish the prediction formula of the flame height in the partial gravity environment.

\section{Experimental Apparatus and Methods}

Arbitrary partial gravity experiments were performed using the drop tower facility at Hi-rosaki University [10] [11]. When the test package falls free, the microgravity field is established in the falling test package. But, for the case of our drop tower, the stainless wire is tied to the drop package, and the other end of it is tied to counterweight. When test package falls, the fall acceleration becomes smaller than $9.8 \mathrm{~m} / \mathrm{s}^{2}$. As a result, the partial gravity field is established in the test package. When the package falls $8 \mathrm{~m}$, we can keep the low gravity condition for about one second. By controlling the weight of the test package, we can change the gravity level from $0.5 \mathrm{G}$ to $0.7 \mathrm{G}$.

Figure 1 shows a schematic of the experimental apparatus inside the test package, including the measuring system. The fuel pan is made of brass and its diameter is $15-23 \mathrm{~mm}$. To investigate the differences of flame characteristics between non-luminous flame and luminous, two kinds of fuel, namely Ethanol and Acetone were used as test fuels. To suppress fuel boiling, the fuel pan was set inside a cooling bath filled with temperature-modulated water. The fuel level was kept at the upper rim of the pan using a level controller. A digital camera (CASIO, EX-F1, 30 fps) recorded the flame behavior of the pool fires. An LED light source was attached to reveal the timing at which the test package fell. All experiments were performed $1 \mathrm{~min}$ after ignition, because preliminary tests under normal gravity showed that the pool fire became stable within about $1 \mathrm{~min}$

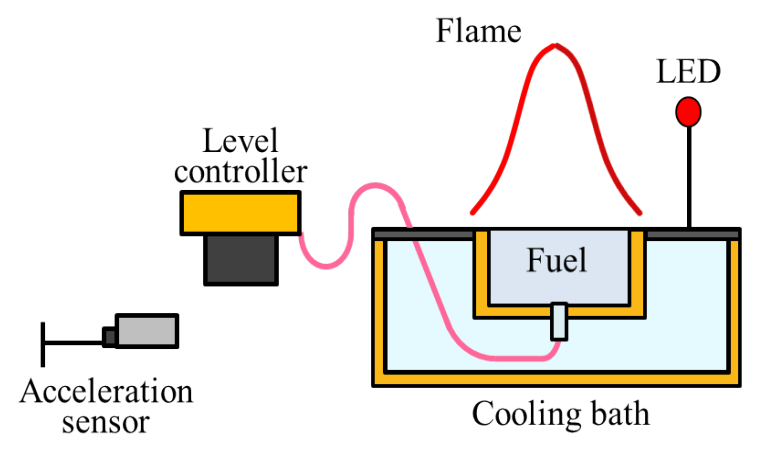

Figure 1. Experimental apparatus. 
after ignition.

\section{Results and Discussion}

\subsection{Effect of Gravity on Flame Height and Flame Surface Area}

The distance from the fuel surface to the top of the luminous flame is defined as the flame height $H$. The flame surface area obtained from the image is defined as $S$. In $1 \mathrm{G}$ and $0.55 \mathrm{G}$, the flame heights are defined as $H_{1}$ and $H_{0.55}$, The flame surface area are defined as $S_{1}$ and $S_{0.55}$. Figure 2 shows relationship between $H_{0.55} / H_{1}$ and $S_{0.55} / S_{1}$ and pool diameter.

From previous research, it is clear that the flame height of pool fires decreases under partial gravity environments [10] [11]. Acetone which is a luminous flame has a lower rate of decrease in flame height. Because, the luminous flame has lager rate of radiative heat feedback, the influence of the decrease of the gravity value was small. On the other hand, the ethanol flame at $\mathrm{d}=18,20,23$, the $S$ was reduced in the partial gravity environment. But under other conditions $S$ has expanded. From Nakajima's study [12], in the burner flame, the flame surface area is expanded in partial gravity environment. Because, air inflow decreases as natural convection is weakened in partial gravity environment, the flame sheet is moved oxygen side by diffusion. In the pool fire, since the amount of fuel evaporation also decreases due to the decrease in the amount of heat feedback. It is considered that the flame surface does not move to the oxygen side as the burner flame.

\subsection{The Amount of Heat Feedback}

\subsubsection{Calculation Method}

We calculate the amount of heat feedback at each pool diameter. Calculation method was based on Yoshida's research [13]. There are two types of heat feedback: convection and radiation. From Yoshihara's study [10], Figure 3 shows flow rate of air around flame. It is clear that, the flow rate of air decrease around

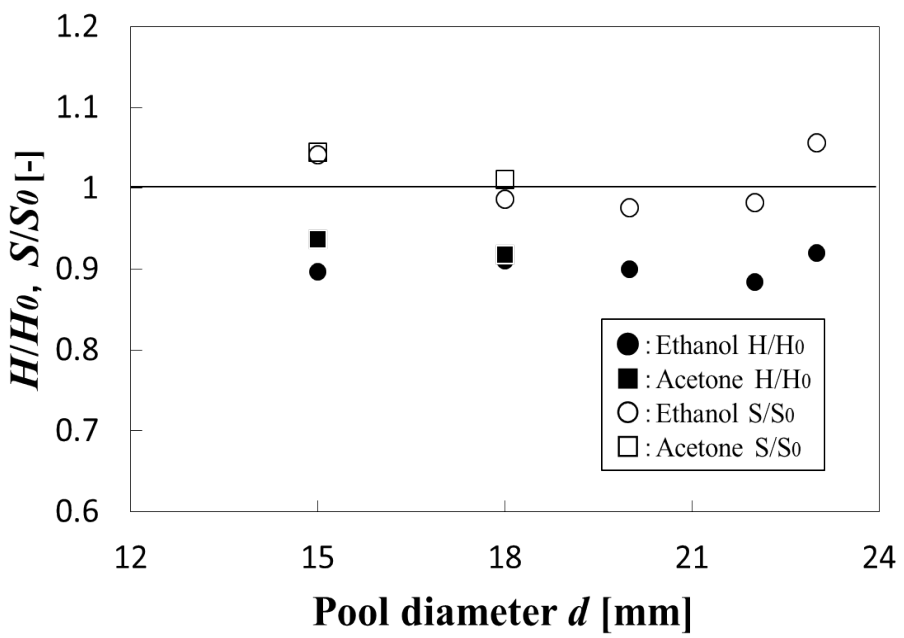

Figure 2. Flame height and surface area ratio at $1 \mathrm{G}$ and $0.55 \mathrm{G}$. 

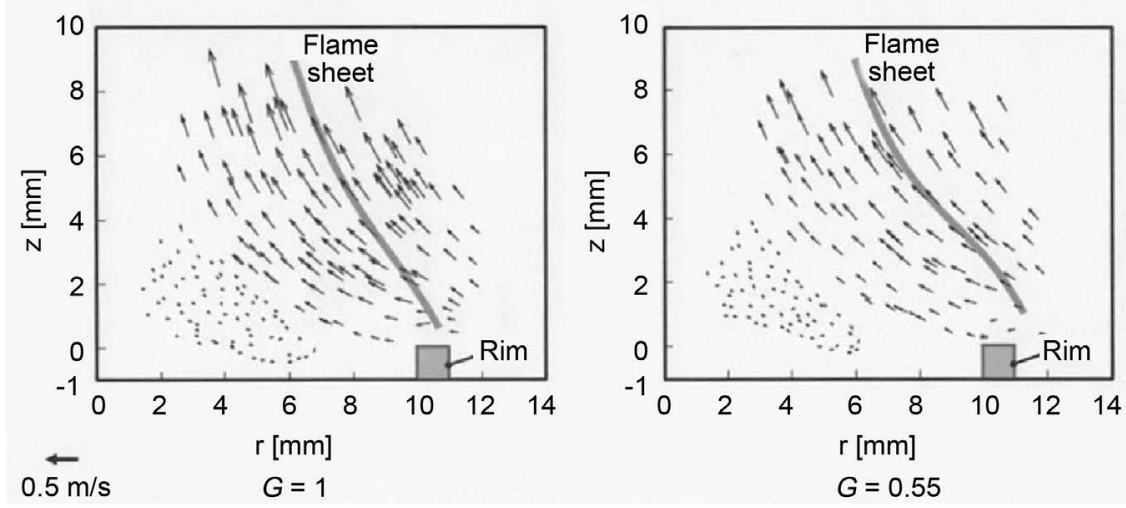

Figure 3. Profiles of two-dimensional velocity field for $20 \mathrm{~mm}$-diameter (acetone).

flame by gravity level decrease, but it near the center of the flame base is less influenced by the decreasing of the gravity level. Therefore, it is expected that the amount of convective heat feedback near the center of the flame base is less influenced by the decreasing of the gravity level. In this study, it is assumed that flame distribution of center of flame does not change. From previous research, it anticipated temperature distribution as Figure 4. We assumed that temperature distributions at other pool diameters were similarly, and obtained the amount of convective heat feedback.

The amount of radiative heat feedback was calculated using the representative flame temperature (ethanol $\mathrm{G}=1: 1190 \mathrm{~K}, \mathrm{G}=0.55: 1128 \mathrm{~K}$, acetone $\mathrm{G}=1: 1222$ $\mathrm{K}, \mathrm{G}=0.55: 1188 \mathrm{~K}$ ) which obtained by the previous study [13]. It was calculated by radiation absorption model [14] [15] [16] using images of flames obtained by experiments.

\subsubsection{Calculation Result}

Figure 5 shows the heat flux which is the sum of convective and radiative heat flux at each pool diameter. In both ethanol and acetone, the heat flux tended to decrease as $d$ increased. It is because the heat flux due to convection decreases as the flame surface and the fuel center are separated from each other. The difference in heat flux between $1 \mathrm{G}$ and $0.55 \mathrm{G}$ is reduced. It is considered that this is because the proportion of heat flux due to radiation with a small influence of the decrease in gravity level becomes relatively large.

The heat flux multiplied by the area of each heat receiving surface is taken as the amount of heat feedback from the flame to the liquid surface and is shown in Figure 6.

\subsection{Calculation of Fuel Flow Rate}

In this research, we assumed the liquid phase of the fuel as steady, and considered the response of an infinitely thin fuel surface. Experiments of this study were performed after $1 \mathrm{~min}$ because the flame stabilized after $1 \mathrm{~min}$. At the same time, we can also consider that this period is when the liquid phase of the fuel becomes steady. Based on this assumption, we can ignore sensible heat and heat 


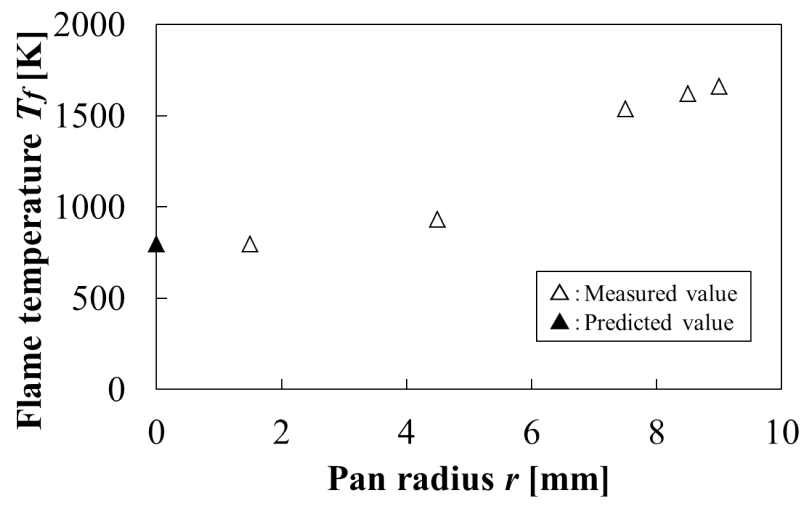

Figure 4. Flame temperature distribution of ethanol $(\mathrm{d}=18)$.

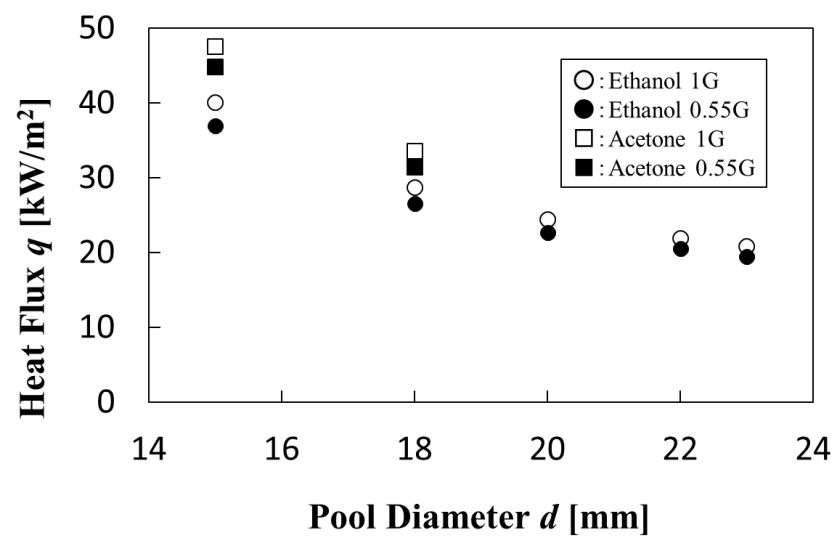

Figure 5. Heat flux at each pool diameter.

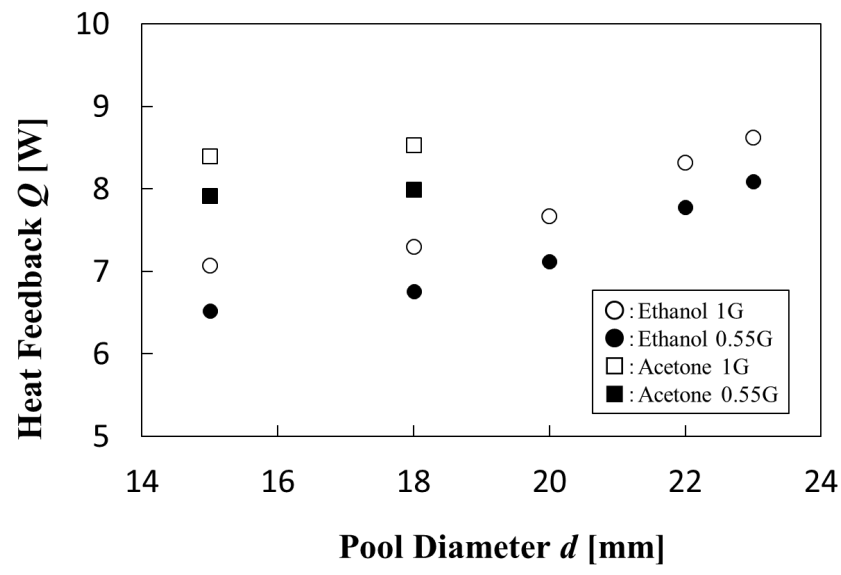

Figure 6. The amount of heat feedback at each pool diameter.

loss. It is assumed that a pool flame is a jet diffusion flame that blows evaporated fuel. The amount of heat feedback which determined in Section 3.1 is used as the amount of heat flowing into the liquid surface. By dividing it by evaporation latent heat (ethanol: $854.8 \mathrm{~kJ} / \mathrm{kg}$, acetone: $551.9 \mathrm{~kJ} / \mathrm{kg}$ ), the mass flow rate of the fuel vapor from the fuel liquid surface is obtained. Calculate the volumetric flow rate of fuel vapor by dividing the mass flow rate by the density of fuel (ethanol: 
$2.074 \mathrm{~kg} / \mathrm{m}^{3}$, acetone: $2.614 \mathrm{~kg} / \mathrm{m}^{3}$ ). The flow velocity of the fuel vapor can be obtained by dividing the volumetric flow rate by the area of the fuel surface. Figure 7 shows the relationship between the fuel vapor flow rate $V_{f}[\mathrm{~m} / \mathrm{s}]$ and the pool diameter $d[\mathrm{~mm}]$.

Since the flow velocity of the fuel vapor depends on the heat flux, it tends to be close to Figure 5. However, because two fuel have different latent heat of evaporation, the flow velocity of fuel vapor is larger than the difference of heat flux at the same pool diameter.

\subsection{Derivation of Prediction Formula of Flame}

\subsubsection{Prediction Formula with Gravity as a Parameter}

Regarding the flame height with the gravity level G as the experimental parameter, Altenkirch derived the following equation [17] [18] [19].

$$
L_{f} /\left\{r_{0}\left(R e^{2} F r\right)^{\frac{1}{3}}\right\}=\frac{1}{F r}
$$

$L_{f}[\mathrm{~mm}]$ is the flame length (the distance from the base of the flame to the tip of the luminous flame), and $r_{0}[\mathrm{~mm}]$ is the radius of the burner tube. The Froude number Fr is a dimensionless quantity that is used in relation to the motion of the fluid affected by the gravitational field and represents the magnitude relation between the inertial force and the gravity. Reynolds number $R e$ is a dimensionless number representing the ratio of inertial force to viscous force. I want to organize the pool fire which is assumed as jet diffusion flames by same way.

We would like to organize the pool flames assumed as jet diffusion flames in Section 3.3, in the same way as Altenkirch. However, in this study, we should consider flame shape change due to buoyancy rather than inertia in order to deal with flames with a particularly small jet velocity. Therefore, Altenkirch's formula is modified as follows.

$$
\frac{H}{d} \frac{1}{C}(R i)^{2 / 3}=R i
$$

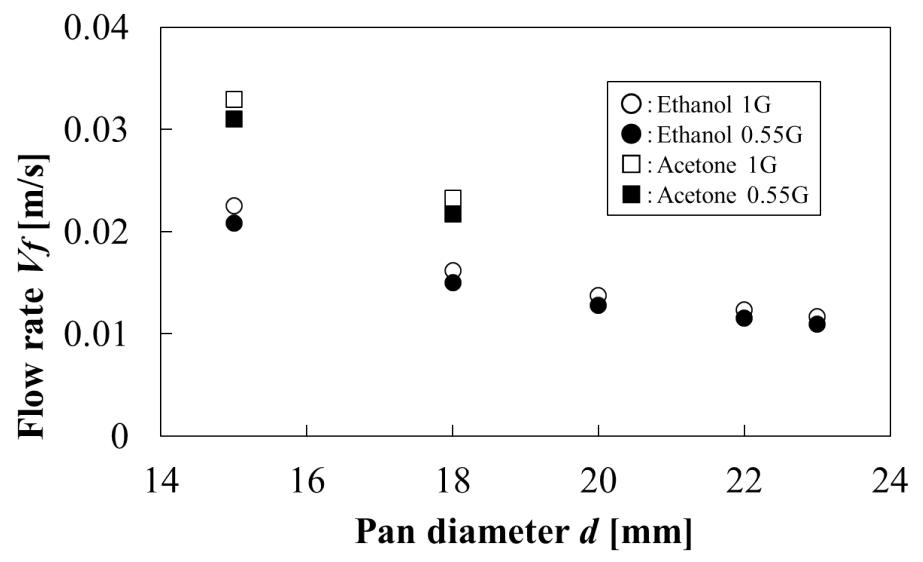

Figure 7. The fuel vapor flow rate at each pool diameter. 
$C$ is the value obtained by dividing $1 \%$ of the combustion heat for each fuel type by the evaporation latent heat. It is assumed that $1 \%$ of the calorific value is used for fuel evaporation, and the flame height variation due to the fuel type is corrected. Richardson number $R i$ is a dimensionless number representing the ratio of buoyant force and inertial force, it is defined by the following equation using Grashof number $G r$ and Reynolds number Re.

$$
R i=\frac{G r}{R e^{2}}
$$

Grashof number $\mathrm{Gr}$ is a dimensionless parameter that dominates natural convection due to buoyant force, it is defined by the following equation.

$$
G r=\frac{g \beta\left(T_{f}-T_{\infty}\right) d^{3}}{v^{2}}
$$

$\beta$ is the coefficient of cubic expansion, $T_{f}$ is the flame temperature $[\mathrm{K}]$, $T_{\infty}$ is the ambient temperature $[\mathrm{K}]$, and $v$ is the kinematic viscosity coefficient $\left[\mathrm{m}^{2} / \mathrm{s}\right]$. Flame is a state in which fuel and air are mixed, but it is difficult to estimate the ratio. Therefore, the values of $\beta$ and $v$ were substituted as the physical property values of air at the respective flame temperatures in this study. Reynolds number Re is defined by the following equation.

$$
R e=\frac{V_{f} d}{v}
$$

Using the above parameters, the influence of Richardson number on flame height and the pool diameter in laminar combustion region without Puffing was summarized. Figure 8 shows it. It was able to unify by the Richardson number. In this way, in the laminar combustion region without Puffing, it was possible to obtain a prediction formula that can express the behavior of flame height with respect to normal gravity and partial gravity.

\subsubsection{Derivation of Prediction Formula}

From the inclination of the straight line in Figure 8 the formula for $\frac{H}{d}$ is ob-

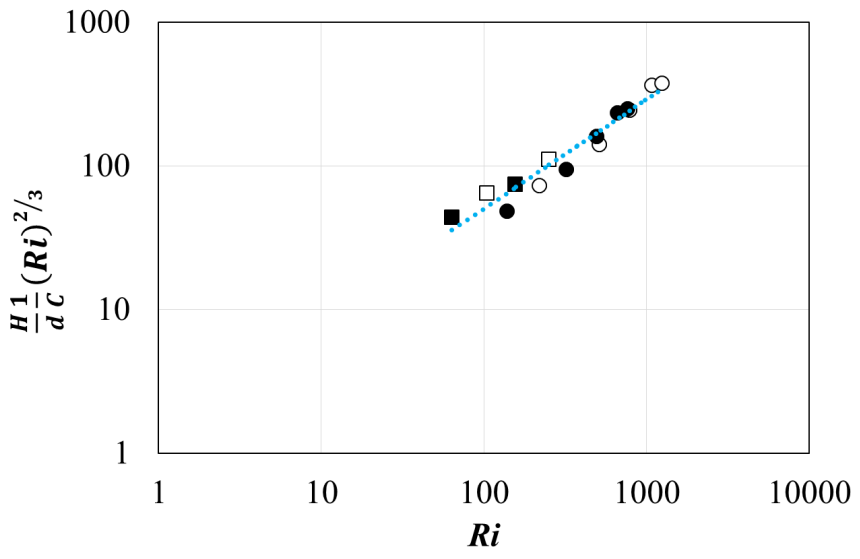

Figure 8. The fuel vapor flow rate at each pool diameter. 
tained as follows.

$$
\frac{H}{d}=1.50 C R i^{0.1}
$$

$\frac{H}{d}$ is proportional to Richardson number $R i$ to the power of 0.1 . In other words it is inversely proportional to Grherhof number Gr to the power of 0.1 , and Reynolds number Re to the power of 0.2 . Since it is proportional to Grashof number, the flame height $\mathrm{H}$ also decreases as the gravity level $\mathrm{G}$ decreases. This is consistent with the experimental result.

\subsubsection{Effective Range of Prediction Formula}

As the gravity level decreases, at transport of fuel and oxidizer, the diffusion become that it is more dominant than buoyancy. Therefore, in the microgravity environment, the prediction formula obtained in Section 3.4.2 may not be valid. Figure 9 shows the prediction formula obtained in Section 3.4.2 and the value obtained by substituting $H / d=0.5$ into the prediction formula. Where the number of Richardson is around 1 to 0.1 , the magnitude relation between them is reversed. It becomes $H / d=0.5$, and the flame height never decreases any further. Therefore, if Richardson number is lower than this, the prediction formula is considered to be not available. The value of the Richardson number is obtained as follows using the Equation (6).

$$
R i=\left(\frac{0.333}{C}\right)^{0.1}
$$

The experimental formula is valid within the range of $R i>\left(\frac{0.333}{C}\right)^{0.1}$.

\section{Conclusions}

In this study, we estimated the amount of heat feedback of small-scale pool fire, and obtained the experimental formula that in order to expect the flame height. The following conclusions are summarized here.

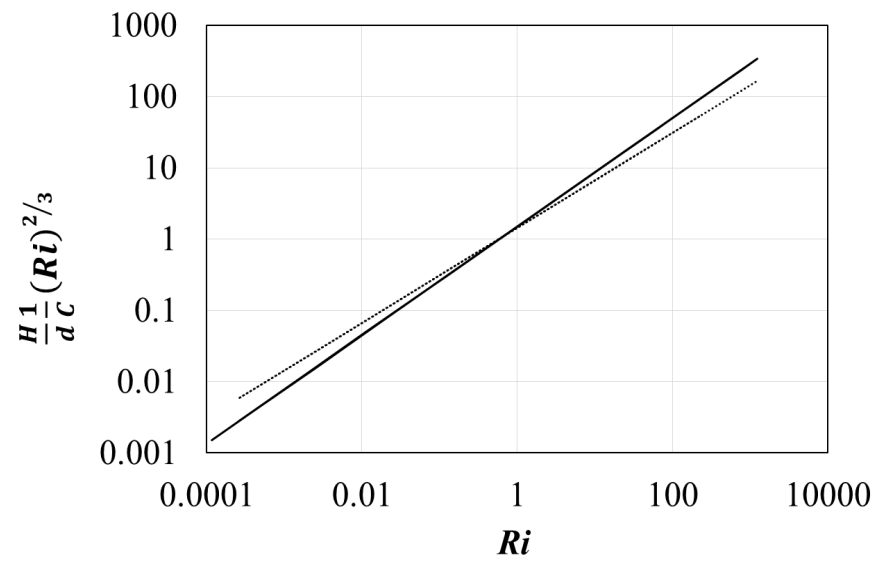

Figure 9. Comparison with prediction formula at $H / d=0.5$. 
1) The flame height of the pool flame decreases in the partial gravity environment, but the surface area does not shrink unconditionally.

2) For a laminar flow diffusion flame without Puffing, we could obtain an experimental formula that expresses the relation of the flame height. It is proportional to the number of Richardson's number 0.1.

3) In the microgravity environment, diffusion of fuels and oxidizing dominates rather than buoyancy. Therefore, the range of the number of Richardson that the prediction formula derived in this study is effective is $R i>\left(\frac{0.333}{C}\right)^{0.1}$.

\section{References}

[1] Orson, S.L. (1987) The Effect of Microgravity on Flame Spread over a Thin Fuel. NASA TM-100195.

[2] Ramachandra, P.A., Altenkirch, R.A., Bhattachajee, S., Tang, L., Sacksteader, K. and Wolverton, M.K. (1995) Combustion and Flame, 100, 71-84.

[3] Shipp, M. and Spearpoint, M. (1994) Fire Safety Science. Proceedings of the 4th International Symposium, 739-750.

[4] West, J., Tang, L., Altenkirch, R.A., Bhattachajee, S., Sacksteader, K. and Delichatsios, M.A. (1996) Proceedings of the Combustion Institute, 26, 1335-1343.

[5] Friedman, R. and Urdan, D.L. (1993) Contributions of Microgravity Test Results to the Design of Spacecraft Fire-Safety Systems. AIAA Paper, 93-1152.

[6] Sanchez Tafira, C., Linan, A., Salva, J.A., Conchero, G., Juste, G.L. and Esteban, F. (1989) Combustion Experiments During KC-135 Parabolic Flights, ESA SP-1113, 53-64.

[7] Bryant, D. and Judd, M.D. (1995) Proceedings of the 10 th Anniversary of First ESA Parabolic Flight Campaign Workshop, ESA, 99-101.

[8] Kashiwagi, T., Mcgrattan, K.B., Olson, S.L., Fujita, O., Kikuchi, M. and Ito, K. (1996) Proceedings of the Combustion Institute, 26, 1345-1352.

[9] Sato, H., Amagai, K. and Arai, M. (2008) Scale Modeling of Puffing Frequencies in Pool Fires Related with Froude Number. Progress in Scale Modeling, Springer, 133-147.

[10] Yoshihara, N., Ito, A. and Torikai, H. (2013) Proceedings of the Combustion Institute, 34, 2599-2606.

[11] Abe, H., Ito, A. and Torikai, H. (2015) Effect of Gravity on Puffing Phenomenon of Liquid Pool Fires. Proceedings of the Combustion Institute, 35, 2581-2587. https://doi.org/10.1016/j.proci.2014.05.080

[12] Nakajima, N., Torikai, H. and Ito, A. (2015) Proceeding of the 53rd Symposium Combust. 508-509.

[13] Yoshida, K., Ito, A. and Torikai, H. (2014) Proceeding of the 52nd Symposium Combust. 442-443.

[14] Drysdale, D. (2011) An Introduction to Fire Dynamics. 3rd Edition, John Wiley \& Sons, Hoboken, 182-192. https://doi.org/10.1002/9781119975465

[15] Modak, A.T. (1977) Combust and Flame, 29,177-185.

[16] Fukuda, M., Kudo, Y., Torikai, H. and Ito, A. (2007) Flame Radiation Absorption Model Applicable to Realistic Fires. Proceedings of the Annual Symposium, 56-57.

[17] Rasbash, D.J., Rogowski, Z.E. and Stark, G.W. (1956) Properties of Fires of Liquids. 
Fuel, 35, 94-107.

[18] Burke, S.P. and Schumann, T.E.W. (1928) Industrial \& Engineering Chemistry Research, 20, 998-1004.

[19] Altenkirch, R.A., Eichhorn, R., Hsu, N.N., Brancic, A. B. and Cevallos, N.E. (1976) Proceedings of the Combustion Institute, 16, 1165-1174.

\section{Scientific Research Publishing}

Submit or recommend next manuscript to SCIRP and we will provide best service for you:

Accepting pre-submission inquiries through Email, Facebook, LinkedIn, Twitter, etc. A wide selection of journals (inclusive of 9 subjects, more than 200 journals) Providing 24-hour high-quality service User-friendly online submission system Fair and swift peer-review system Efficient typesetting and proofreading procedure Display of the result of downloads and visits, as well as the number of cited articles Maximum dissemination of your research work

Submit your manuscript at: http://papersubmission.scirp.org/ Or contact ojsst@scirp.org 